\title{
Adsorption of uranium-containing wastewater by Sugarcane Stalks
}

\author{
Yi Xin ${ }^{1, a}$, Wu Deng ${ }^{2, b}$ \\ ${ }^{1,2}$ School of Chemistry and Chemical Engineering, Xi'an University of Science and Technology, \\ Xi'an Shaanxi, China \\ a,byxily1314520@163.com
}

Keywords: Sugarcane stalks; Modification; Adsorption; Uranium; Adsorption Mechanism

\begin{abstract}
Abstrcact. The new sorbent-sugercane stalks on the adsorption of uranium-containing wastewater was studied by static adsorption experiments in this research. Its feasibility and adsorption capacity as a biological adsorbent was verified through modification experiments. The influence of adsorbents dosage, adsorption time and temperature, adsorption solution $\mathrm{pH}$, initial concentration on the adsorption of uranium after the modification was studied and the adsorption mechanism of uranium adsorption by sugarcane stalks was discussed. The experimental results showed that adsorption efficiency increased about $50 \%$ after modification by $\mathrm{ZnCl}_{2}$ and $\mathrm{NaOH}$, and the maximum adsorption efficiency was $86.6 \%$ and the maximum adsorption capacity was $2.5 \mathrm{mg} / \mathrm{g}$ at $303 \mathrm{k}, \mathrm{pH}=3$, the time was ahout 90 mins, modification was feasible. Warming was conductive to the adsorption. The amount of adsorbent to the optimum volume of the solution was $8 \mathrm{~g} / \mathrm{L}$. The results indicated that sugarcane stalks can be used as the good uranium-containing wastewater decontamination biosorbent.
\end{abstract}

\section{Introduction}

With global demand for nuclear fuel increasing, especially for uranium, more and more uranium-containing wastewater was released. Uranium-containing wastewater was radioactive and chemically toxic, so that all countries attached great importance to the treatment processing of uranium-containing wastewater[1] and developed a variety of treatment methods and techniques[2]. A promising new method-biosorption has many advantages[3], came into being. In recent years, researchers in this area had also been studied and tried a variety of adsorbents, such as corn cobs[4], saccharomyctes[5], they have made some progress. China, as the world's third largest sugar cane producing countries, will produce a large number of post-squeezed sugar cane residue, which was burned or discarded directly, resulting in a great waste of resources and environmental pollution.

\section{Materials and Methods}

Instruments and reagents. pHS-3C Precision $\mathrm{pH}$ meter (Shanghai Lei magnetic Instrument Factory); SHC-C.constant temperature water bath oscillator (Jiangsu Jiangnan Instrument Factory); FA1104 electronic balance (accuracy of 0.0001 g), Shanghai Ryohei Instrument Co., Ltd.; ZKF040 Vacuum oven (Shanghai experimental Instrument Co., Ltd.). Reagents: 1 g/L uranium standard solution; hydrochloric acid $(\mathrm{HCl})$, sodium hydroxide $(\mathrm{NaOH})$ and zinc chloride $\left(\mathrm{ZnCl}_{2}\right)$ were analytical grade.

Materials. Cane stalks were purchased in around market and sugar cane bagasse was washed by distilled water after juicing, then it was grounded into powder after drying and dried to constant weight at 80 let it through 40 mesh sieve, put it in the oven to cool and then at dry place after bagging sealed.

Methods. a(non-modified): Take $1 \mathrm{~g} / \mathrm{L}$ uranium standard solution, add distilled water to a solution of different concentrations, and the $\mathrm{pH}$ was adjusted with $\mathrm{HCl}(\mathrm{aq})$ and $\mathrm{NaOH}(\mathrm{aq}), 25 \mathrm{ml}$ pipette with uranium standard solution was added $250 \mathrm{ml}$ conical flask, a certain amount of the adsorbent was added thereto, it was placed in a thermostatic water shaker shaking adsorption certain time at a temperature, taking appropriate supernatant after filtration, remaining uranium 
concentrations in solution was measured by $\mathrm{TiCl}_{3} / \mathrm{NH}_{4} \mathrm{VO}_{3}$ titration[6], calculation adsorption performance parameters. $\mathrm{b}$ (modified): Weigh a quantity of the adsorbent and put into two $250 \mathrm{ml}$ Erlenmeyer flasks, $100 \mathrm{ml}$ of $50 \% \mathrm{ZnCl}_{2}(\mathrm{aq})$ and $0.1 \mathrm{~mol} / \mathrm{L} \mathrm{NaOH}(\mathrm{aq})$ were added. Filtration after oscillating adsorption $12 \mathrm{~h}$, wash and drying. The sorbent modified by $\mathrm{ZnCl}_{2}$ was used in other experimental groups. The amount of the adsorbent $Q(\mathrm{mg} / \mathrm{g})$ to $\mathrm{U}(\mathrm{VI})$ and the removal rate $R(\%)$ were calculated by the following equations:

$$
\begin{aligned}
& \mathrm{Q}=(\mathrm{C}-\mathrm{Ce}) \mathrm{V} / \mathrm{m} \\
& \mathrm{R}=(\mathrm{C}-\mathrm{Ce}) \times 100 \% / \mathrm{C}
\end{aligned}
$$

Formula: $\mathrm{C}=$ initial uranium concentration $(\mathrm{mg} / \mathrm{L})$; $\mathrm{Ce}=$ uranium concentration in solution at equilibrium (mg/L); $\mathrm{V}=$ volume of solution adsorption $(\mathrm{L}) ; \mathrm{m}=$ dry weight (g) of the adsorbent;

\section{Results and Discussions}

Effect of adsorbent dose on adsorption of uranium(VI). At room temperature, the adsorbents(a group: 0.05 g, 0.10 g, 0.15 g, 0.20 g, 0.25 g, 0.30 g; b group: 0.12 g, 0.16 g, 0.20 g, $0.24 \mathrm{~g}$ ) were added to $25 \mathrm{ml}$ solution the concentration $20 \mathrm{mg} / \mathrm{L}$ to oscillate adsorption $12 \mathrm{~h}$. The results of effect of adsorbent dosage on the adsorption of U(VI) were shown in Figure 1.
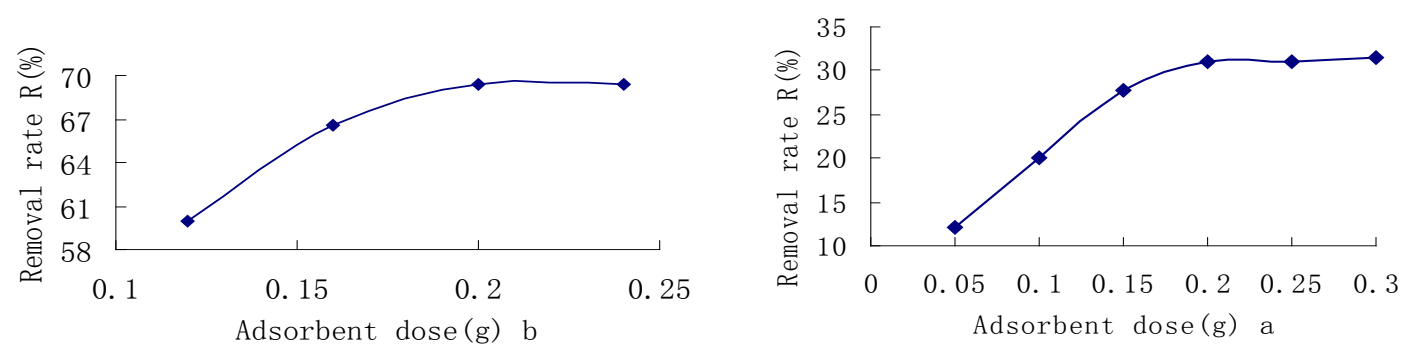

Fig.1 Effect of adsorbent dose on adsorption of uranium(VI)

Figure 1 showed that before and after the modification, the removal rate of U(VI) ions gradually increased with the addition of adsorbent, it reached a maximum at $0.20 \mathrm{~g}$ and then tended to stabilize. The adsorption sites increased as adsorbent was added, so that the removal rate of U(VI) ions increased. Maybe there was a U(VI) concentration equilibrium between solution and within the adsorbent with further increasing of the amount of adsorbent and adsorption came to stabilized[7]. Therefore the best adsorbent amount to solution volume ratio is $8.0 \mathrm{~g} / \mathrm{L}$.

Effect of initial pH value on adsorption of uranium(VI). At room temperature, adding $0.20 \mathrm{~g}$ adsorbent to $25 \mathrm{ml}$ concentration of $20 \mathrm{mg} / \mathrm{L}$ uranium-containing solution and oscillating adsorption $12 \mathrm{~h}$. Changing the initial solution $\mathrm{pH}$ (a group: 1,2,3,4,5,6,7; b group: 2,3,4,5,6) to study the effect of $\mathrm{pH}$ on the adsorption of U(VI), the results were shown in Figure 2.
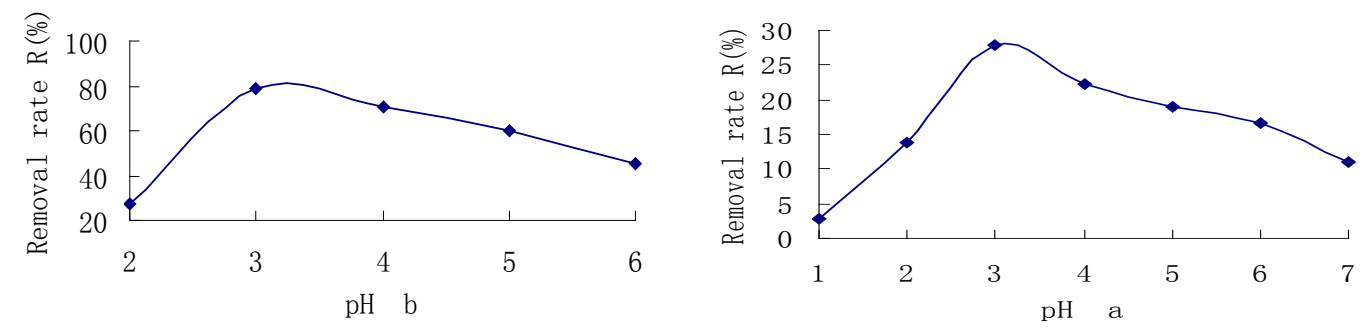

Fig.2 Effect of initial $\mathrm{pH}$ value on adsorption of uranium(VI)

Figure 2 showed that before and after modification, the removal rate of U(VI) changed with the $\mathrm{pH}$ changing, first to rise then to decrease, which has a maximum in the vicinity of $\mathrm{pH}=3$, the adsorption efficiency decreased faster when the $\mathrm{pH}<3$ compared to $\mathrm{pH}>3$ and the maximum removal rate was about $86 \%$ after the significant modification. It explained the removal rate of $\mathrm{U}(\mathrm{VI})$ ions was greatly affected by $\mathrm{pH}$. This was because the $\mathrm{pH}$ of the solution had a significant impact on the adsorption sites of activity and $\mathrm{UO}_{2}{ }^{2+}$ ions in the presence of the state. Under strongly acidic conditions, the solution with $\mathrm{H}^{+}$ions combined with adsorption sites and it impacted the 
adsorption of $\mathrm{UO}_{2}{ }^{2+}$ ions. $\mathrm{UO}_{2}{ }^{2+}$ ions were hydrolyzed to produce other ions resulting in the adsorption capacity decreasing when acidic weakened.

Effect of time on adsorption of uranium(VI). At room temperature, adding $0.20 \mathrm{~g}$ sorbent to the $25 \mathrm{ml}$ concentration of $20 \mathrm{mg} / \mathrm{L}$ uranium-containing solution to oscillate adsorption within the certain time(2h) (a group interval of 10 mins; b group interval 20 mins within $2 \mathrm{~h}$ ). The results of effect of adsorption time on the adsorption of U (VI) were shown in Figure 3.
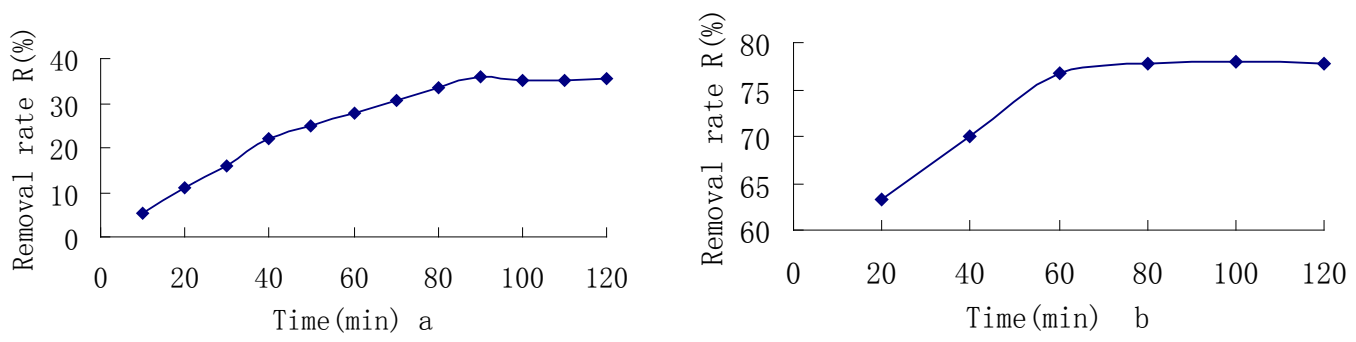

Fig.3 Effect of time on adsorption of uranium(VI)

Figure 3 showed that U(VI) ions removal rate increased with the adsorption time before and after modification, the removal rate of rapid growth within 90 mins generally tended to adsorption equilibrium about 90 mins, increasing the adsorption efficiency of about $40 \%$.

Effect of temperature on adsorption of uranium(VI). Adding $2.0 \mathrm{~g}$ sorbent to $25 \mathrm{ml}$ concentration of $20 \mathrm{mg} / \mathrm{L}$ uranium standard solution to oscillate adsorption 90 mins at $20{ }^{\circ} \mathrm{C}, 30{ }^{\circ} \mathrm{C}, 40{ }^{\circ} \mathrm{C}, 50{ }^{\circ} \mathrm{C}, 60{ }^{\circ} \mathrm{C}$, the results of impact of temperature on adsorption of $\mathrm{U}(\mathrm{VI})$ were shown in Figure 4.

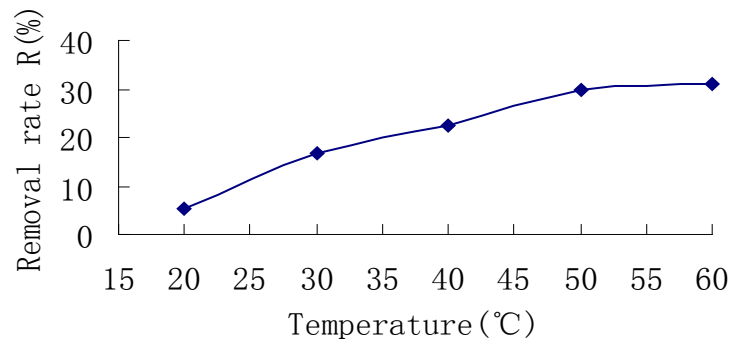

Fig.4 Effect of temperature on adsorption of uranium(VI)

Figure4 showed that $\mathrm{U}(\mathrm{VI})$ ions removal rate increased with increasing temperature. $50 \quad{ }^{\circ} \mathrm{C}$ previous rapid growth and stabilizing at around 50

itas itnirfdicededf warming adsorption. It was because the temperature accelerated the diffusion rate of ions in solution and formed some new adsorption sites in the sorbent to improve the adsorption efficiency.

Effect of initial concentration on adsorption of uranium(VI). At room temperature, adding $0.20 \mathrm{~g}$ of modified adsorbent in $25 \mathrm{ml}$ concentration of $10 \mathrm{mg} / \mathrm{L}, 20 \mathrm{mg} / \mathrm{L}, 30 \mathrm{mg} / \mathrm{L}, 50 \mathrm{mg} / \mathrm{L}, 100$ $\mathrm{mg} / \mathrm{L}$ uranium-containing solution and shaking adsorption $12 \mathrm{~h}$; the results of influence of the initial concentration on adsorption of U (VI) were shown in Figure 5.

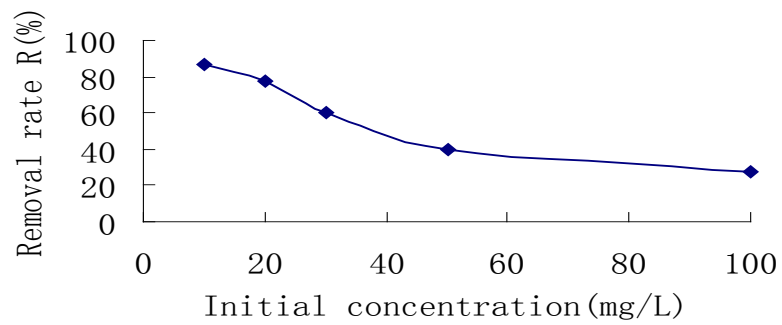

Fig.5 Effect of initial concentration on adsorption of uranium(VI)

As can be seen from Figure 5, U(VI) ions removal rate increased with the decrease of initial concentration, it was because when the uranium concentration in the solution was low and the adsorption sites could be sufficiently contacted with the ions, which had a high removal rate; With concentration of ions in solution increasing, a large number of adsorption sites came to saturated and it resulted in other ions only free in solution, so that the removal rate declined[8]. 


\section{Adsorption Mechanims}

Natural uranium does not exist as the form of ions and mainly in the positive tetravalent and hexavalent positive coexistence with metal compounds or oxides, $\mathrm{U}($ form stable complexes precipitated, and U( uranyl ions, most of the uranium in the solution is adsorbed in the form of $\mathrm{UO}_{2}{ }^{2+}$ ions.

IV) with in 泣) often parti

Cell wall is the main place for the accumulation of metal ions, chemical analysis found that sugar cane stalks containing about 45\% cellulose, 28\% hemicellulose, 18\%[9] lignin. By infrared spectroscopy, we found it contained the functional groups[10] of carbon-carbon double bond, carboxyl group, carbonyl group, ether group, aryl group, phenolic hydroxyl group. For one thing, $\mathrm{UO}_{2}{ }^{2+}$ ions diffused to the reaction interface during adsorption process and reacted esterification, etherification, chelating with functional groups to form a complex or complexes, the most important of which was hydroxyl group and carboxyl group. For another, $\mathrm{UO}_{2}{ }^{2+}$ ions further spreaded within the modified material to exchange reaction[11]. The adsorption efficiency of modified sugar cane stalks increased significantly because its surface of the cells post-treatment contained lignin, cellulose, hemicellulose, and other structures were exposed, these structures provided $\mathrm{UO}_{2}{ }^{2+}$ ions with organic functional groups to occur complexing ligands and to improve the adsorption efficiency[12].

\section{Conclusions}

The results showed that before the modification, the adsorption equilibrium time was 90 mins, the maximum removal rate was about $35 \%$ and the maximum adsorption capacity reached to 1.2 $\mathrm{mg} / \mathrm{g}$; an optimum $\mathrm{pH}$ was 3 and the optimum adsorption temperature was about $50{ }^{\circ} \mathrm{C}$, heating was conductive to the adsorption and the optimum amount of adsorbent to the solution volume ratio was $8.0 \mathrm{~g} / \mathrm{L}$.

The adsorbent have better adsorption effect after $\mathrm{ZnCl} 2$ feasible modified; maximum removal rate of $\mathrm{U}(\mathrm{VI})$ ions was about $86 \%$, the maximum adsorption capacity reached to $2.5 \mathrm{mg} / \mathrm{g}$, adsorption equilibrium time and optimal $\mathrm{pH}$ were substantially identical before and after modification. Adsorption efficiency decreased with the increasing of initial concentration of U(VI) and adsorption efficiency increased with adsorbent dosage increasing under certain initial concentration.

\section{References}

[1]Li, Q.F. \& Liu, M.X. 2008. Environmental Science \& Technology 31(10): 67-70.

[2]Wei, G.Z. \& Xu, L.C. 2007. Uranium Mining and Metallurgy 26(2): 90-95.

[3]Aloysius, R. \& Karim, M.I.A. 1999. World J. Microbiol. Biotechnol 15(5):571-578.

[4]Li, X.Y. \& Hua, M. 2012. Chemical Technology (12): 1-7.

[5]Liu, M.X. \& Dong, F.Q. 2009. Environmental Science \& Technology 32(5): 31-34.

[6]EJ 267.3 - 1984, Determination of Uranium in Uranium Ore.

[7]Wang, X. \& Xia, L.S. 2010. The Chinese Journal of Process Engineering 10(6): 1084-1090.

[8]Feng, Y. \& Yi, F.C. 2011. Atomic Energy Science and Technology 45(2): 161-167.

[9]Garg, U. \& Kaur, M.P. 2008. Journal of Hazardous Materials 154(1-3): 1149-1157.

[10]Garg, U.K. \& Kaur, M.P. 2007. Journal of Hazardous Materials 140(1-2): 60-68.

[11]Zhou, S.K. \& Zeng, G.M. 2011. China Environmental Science 31(9): 1466-1471.

[12]Wang, X. 2011. Hengyang: University of South China. 